\title{
Relações Internacionais Federativas no Brasil
}

\author{
Gilberto Marcos Antonio Rodrigues
}

\begin{abstract}
s relações internacionais de governos subnacionais ${ }^{1}$ constituem A um dos fenômenos mais desconcertantes do federalismo na atualidade pela seguinte razão: as relações internacionais, em geral, e a política externa, em particular, são possivelmente o espaço de atuação estatal e de formulação de políticas públicas em que o Estado-nação mais zela por exercer monopólio, coerência e controle.

Conhecido na literatura como paradiplomacia, o fenômeno das relações internacionais de governos subnacionais não se restringe a países federais. Entretanto, nas federações, Estados federados, províncias e municípios $^{2}$ vêm atuando com desenvoltura no plano externo e aumentando sua inserção internacional de muitas formas, a olhos vistos. Se tal fenômeno social e político não apenas existe, mas se amplia, é imperativo estudá-lo e compreendê-lo em sua legitimidade e legalidade, e em seu exercício no âmbito das federações.
\end{abstract}

Seguindo essa perspectiva, neste artigo é proposta a análise das relações internacionais federativas no Brasil, de seus Estados federados e municípios a partir de um conjunto de enfoques complementares e interdependentes: 1) questões constitucionais; 2) relações intergovernamentais; 3) política externa (ou relações exteriores); 4) legitimidade e accountability.

DADOS - Revista de Ciências Sociais, Rio de Janeiro, Vol. 51, nº-4, 2008, pp. 1015 a 1034. 
Essa metodologia de análise foi utilizada pela organização internacional Fórum das Federações ${ }^{3}$, em um projeto denominado Dialogues on Foreign Relations in Federal Countries, realizado sob a coordenação do professor Hans Michelmann e concluído em outubro de 2006, constituindo parte da atuação global dessa organização (Blindenbacher e Pasma, 2007). Da América Latina e Caribe, apenas a Argentina foi incluída nesse projeto. Valendo-se da mesma metodologia, neste artigo, busca-se realizar essa análise e contribuir com a visão e o debate nacionais e internacionais sobre o caso brasileiro.

\section{QUESTÕES CONSTITUCIONAIS}

A pergunta-chave deste tópico é: até que ponto é necessário constitucionalizar as relações internacionais federativas como forma de reconhecimento de sua legitimidade e de abrigo de sua legalidade? Naturalmente, trata-se de uma indagação que remete a um pano de fundo da seara da filosofia do direito, da teoria geral do Estado e da ciência política, a saber: até que ponto é necessário constitucionalizar um direito para torná-lo real e efetivo?

Cabe aqui verificar alguns exemplos relevantes do direito constitucional comparado e o que nos indica o direito constitucional brasileiro.

\section{Direito Constitucional Comparado}

Quando se conhecem as molduras constitucionais e as experiências e práticas dos países federais, depara-se com inesperada diversidade. Se se toma a estrutura do Estado - um dos componentes essenciais de toda a Constituição -, existem Estados federais com alta, média e baixa descentralização. O grau de descentralização do Estado federal depende de vários fatores - de natureza histórica, cultural, lingüística ou étnica -, ligados ou não à maneira como se constituiu o federalismo (por agregação ou segregação).

No caso suíço, por exemplo, a Constituição Federal da Confederação Helvética (de 1874, com emendas) prevê, de forma excepcional, que os cantões (cantons) têm o direito de concluir tratados com Estados estrangeiros, em matéria de economia do setor público, relações de vizinhança e polícia, tal como expressa o art. 9o da Carta Helvética: Exceptionnellement, les cantons conservent le droit de conclure, avec les Etats étrangers, des traits sur des objects concernant l'économie publique, les rapports des voisinage et de police; [...] (Suisse, 1997).

\section{6}


Já no caso alemão, a Constituição da República Federal da Alemanha (de 1949, com emendas) reconhece tanto o direito a ser consultado quanto o treaty-making power aos Estados federados alemães (Lünder), em seu art. 32, cujo texto diz:

\section{(Relações estrangeiras)}

(1) Compete à Federação estabelecer as relações com Estados estrangeiros.

(2) Antes de se concluir um tratado que afete as condições especiais de um "Land", este deverá ser ouvido com a devida antecedência.

(3) No âmbito da sua competência legislativa e com o consentimento do Governo Federal, os "Lander" poderão concluir tratados com Estados estrangeiros (Alemanha, 1996; ênfase do autor).

Há um entendimento - e uma prática política - de que os governos subnacionais podem atuar internacionalmente no âmbito de sua autonomia federativa, ou seja, no campo balizado de suas competências constitucionais expressas, sendo elas exclusivas ou comuns, desde que não contrariem o interesse nacional ou invadam a seara da alta política (high politics), ou seja, o núcleo duro das relações internacionais do Estado. Pode-se tomar como parâmetro as relações diplomáticas e consulares, o reconhecimento de Estado e de governo, e o campo da defesa. No Brasil, parte da literatura especializada sustenta essa idéia (Vigevani et alii, 2004; Rodrigues, 2004; 2006).

Exemplificando, um governo subnacional não poderia manter relações internacionais com as autoridades de um território estrangeiro não reconhecido como Estado (por exemplo, Taiwan) ou cujo governo não tenha sido reconhecido como legítimo ou legal (por exemplo, um governo golpista). Por outro lado, nada impede que governos subnacionais tenham representação em outros países e se beneficiem de facilidades e privilégios do Estado hospedeiro (caso da província canadense do Quebec, cuja missão permanente em Paris obteve status diplomático do governo francês).

A experiência européia das relações internacionais federativas se desenvolveu e se consolidou, em grande medida, sob o amparo e a inspiração do princípio da subsidiaridade (o regional ou local atua em nome do nacional). Esse princípio, basilar do direito comunitário, ganhou mais força com o aggiornamento da União Européia e a criação do Comitê de Regiões, pelo Tratado de Maastricht (1992), que institucionalizou a participação dos governos subnacionais na política comuni- 
tária européia, aprofundando a relação entre regionalismo e democracia (Stuart, $\mathrm{s} / \mathrm{d}$ ). Isso explica o fato de muitos governos subnacionais europeus manterem escritório de representação em Bruxelas.

Na América Latina, além do Brasil, outros três países federais - Argentina, México e Venezuela - seriam facilmente classificados na categoria "mais centralizados" até os anos 1980. Porém, desde então, o processo de redemocratização desses países, saídos de regimes autoritários ou fechados (com exceção da Venezuela), modificou sua estrutura estatal, que se tornou mais descentralizada, em um processo conhecido como devolução de competências (Carrillo Flórez, 2001).

De todos esses países, a Argentina foi o único em que uma ampla reforma constitucional, realizada em 1994, inaugurou a cláusula constitucional da paradiplomacia. Com efeito, é reconhecido às províncias argentinas, a partir de então, o treaty-making power, com alguns limites, de acordo com o art. 124 da Constituição da Nação Argentina:

Las provincias podrán crear regiones para el desarrollo económico y social y establecer órganos con facultades para el cumplimiento de sus fines y podrán también celebrar convenios internacionales en tanto no sean incompatibles con la política exterior de la Nación y no afecten las facultades delegadas al Gobierno federal o el crédito público de la Nación; con conocimiento del Congreso Nacional. La ciudad de Buenos Aires tendrá el régimen que se establezca a tal efecto (Argentina, 1995; ênfase do autor).

O caso argentino se insere em um debate constitucional mais amplo entre centralistas e provincialistas desse país, cuja profundidade não encontra paralelo na região. Por outro lado, a novidade do reconhecimento constitucional da paradiplomacia argentina despertou o tema na América Latina e produziu eco no Brasil ${ }^{4}$.

Na relação entre as ordens jurídicas nacionais e internacional, percebe-se uma crescente lacuna entre o reconhecimento da legitimidade das ações internacionais de governos subnacionais de Estados federais e sua contrapartida no direito internacional, para o qual os governos subnacionais não existem como sujeitos. Nas palavras de Rezek (2005:234), "Estados federados, exatamente por admitirem sua subordinação a uma autoridade e a uma ordem jurídica centrais, não têm personalidade jurídica de Direito Internacional público, faltando-lhes, assim, capacidade para exprimir voz e vontade próprias na cena internacional". 
Daí se pode entender que os acordos internacionais entre governos subnacionais e entre estes e Estados estrangeiros não sejam regidos pela Convenção de Viena sobre Direito dos Tratados, de 1969, ou seja: não seriam tratados (treaties), mas acordos ou convênios (agreements), uma espécie de contrato sui generis ${ }^{5}$. O problema, bem como a citada lacuna, apresenta-se à medida que as relações internacionais subnacionais/federativas se multiplicam vertiginosamente no cenário internacional globalizado e seus instrumentos convencionais permanecem em uma espécie de limbo jurídico.

\section{Direito Constitucional Brasileiro}

A Constituição Federal-CF, de 1988, em suas mais de cinqüenta emendas $^{6}$, não prevê a possibilidade de que Estados federados, Distrito Federal e municípios desenvolvam relações internacionais.

O art. 21 da CF determina que "compete à União: I - manter relações com Estados estrangeiros e participar de organizações internacionais". Já o art. 84 dispõe que "compete privativamente ao Presidente da República: VII - manter relações com Estados estrangeiros e acreditar seus representantes diplomáticos; VIII - celebrar tratados, convenções e atos internacionais, sujeitos a referendo do Congresso Nacional" ${ }^{\prime 7}$.

De acordo com o princípio dos pesos e contrapesos, o art. 49 da CF prevê ser da competência exclusiva do Congresso Nacional "I - resolver definitivamente sobre tratados, acordos ou atos internacionais que acarretem encargos ou compromissos gravosos ao patrimônio nacional"; e o Poder Judiciário exerce o controle de constitucionalidade de tais atos (art. 105).

Todavia, a Constituição não é totalmente silenciosa sobre o tema na ótica federativa. $\mathrm{O}$ art. 52, tratando de competências privativas do Senado Federal, estatui, no inciso V, competir à câmara alta "autorizar operações externas de natureza financeira, de interesse da União, dos Estados, do Distrito Federal, dos Territórios e dos Municípios". O efeito prático desse inciso se revela nas negociações diretas que vários Estados federados e municípios brasileiros vêm mantendo, desde os anos 1990, com organismos econômicos internacionais, como o BIRD e o BID, e o próprio Programa das Nações Unidas para o Desenvolvimento - PNUD. 
O fato de ser uma Federação trina - formada por três entes federados, a União, os Estados e os municípios - é um diferencial do caso brasileiro. A partir da CF de 1988, os municípios tornaram-se entes federados, equiparados à União e aos Estados, com competências próprias e comuns aos demais entes. Pouquíssimos países federais são trinos; na América Latina, apenas o Brasil.

Curiosamente, mesmo sem previsão constitucional, a paradiplomacia tem sido praticada diariamente, sem necessariamente afrontar o Estado de direito. Exemplos concretos de atuação estadual e municipal ocorrem no âmbito das competências comuns, definidas no art. 23 da CF (que inclui os temas saúde; patrimônio histórico, cultural e paisagístico; cultura, educação e ciência; meio ambiente; habitação; e combate à pobreza). Por exemplo: é crescente a quantidade de convênios de cooperação técnica entre municípios e Estados federados brasileiros e contrapartes estatais estrangeiras para implementar políticas públicas de proteção ambiental tendo por base tratados ou documentos internacionais - como o Protocolo de Kyoto (1997), em relação ao aquecimento global ${ }^{8}$, ou a Agenda 21, em relação ao desenvolvimento sustentável.

Em 2005, a primeira tentativa de constitucionalizar a paradiplomacia no Brasil teve lugar na Câmara Federal. O exemplo do caso argentino e o aumento de interesse e de ações internacionais de governos subnacionais brasileiros - somados à suposta necessidade de conferir legalidade a essas ações - levaram o então deputado federal André Costa (Partido Democrático Trabalhista - PDT-RJ), diplomata de carreira, a apresentar uma Proposta de Emenda Constitucional - PEC (475/2005) para introduzir a cláusula paradiplomática. A "PEC da Paradiplomacia" propôs acrescentar o $\S 22^{\circ}$ ao art. 23 da CF, com o seguinte teor: "Os Estados, Distrito Federal e municípios, no âmbito de suas competências, poderão promover atos e celebrar acordos ou convênios com entes subnacionais estrangeiros, mediante prévia autorização da União, observado o art. 49, I, e na forma da lei".

O texto da PEC é claramente inspirado nas constituições alemã e argentina; porém, adota severas restrições inexistentes nestas: 1) as contrapartes somente poderiam ser entes subnacionais estrangeiros (descartados os Estados nacionais estrangeiros); 2) necessidade de autorização prévia da União (limitação à autonomia federativa); 3) exigência de aprovação congressual (controle legislativo federal). Comparada 
com seus modelos inspiradores, a proposta brasileira é fortemente restritiva à paradiplomacia.

O maior problema do texto da PEC é a exigência de autorização prévia da União. Trata-se de um limitador que fere o princípio da autonomia federativa - considerando que o texto se insere nas competências comuns -, com sério risco de inviabilizar o exercício das ações internacionais de Estados e municípios brasileiros.

A PEC recebeu parecer contrário do relator da Comissão de Constituição e Justiça e de Cidadania (deputado Ney Lopes/Partido da Frente Liberal - PFL-RN) - que a considerou inconstitucional - e foi arquivada no início da legislatura seguinte do Congresso, em janeiro de 2007. Embora não tenha prosperado, a PEC da Paradiplomacia demonstrou não ser fácil constitucionalizar as relações internacionais federativas no Brasil, assim como manter o equilíbrio do princípio federativo. Conquanto problemática em sua proposição, ela tem o inegável mérito de lançar oficialmente uma reflexão sobre o tema.

No terreno estrito da legalidade da paradiplomacia brasileira, avançam as discussões oficiais para se criar um marco legal que a incorpore e fixe balizas de atuação. Em geral, os diplomatas e juristas que têm discutido esse assunto (Lessa, 2002; Medeiros, 2007; Branco, 2008) defendem que o país tenha uma lei para regular a celebração de tratados e, dessa forma, impor limites à atuação paradiplomática. Com efeito, um Projeto de Lei (PL-98/2006) de autoria do senador Antero Paes de Barros (Partido da Social Democracia Brasileira - PSDB-MT), ora em tramitação, propõe-se a instituir a moldura legal do processo de celebração de tratados ${ }^{9}$.

Contudo, retomando a indagação inicial, em termos mais específicos: será mesmo útil e necessário constitucionalizar a paradiplomacia brasileira? Caso positivo, como fazer isso respeitando a autonomia federativa? A questão constitucional permanece aberta ao debate.

\section{RELAÇÕES INTERGOVERNAMENTAIS}

Um dos aspectos fundamentais de uma Federação é a existência de mecanismos de relacionamento entre os entes federados verticais (União-Estados-Municípios) e horizontais (Estados-Estados, Municípios-Municípios). Esses mecanismos são elos essenciais tanto para a coordenação quanto para a cooperação federativa. Assim, dois pontos 
cruciais deste tópico são: há mecanismos intergovernamentais para lidar com a agenda internacional do país? As relações intergovernamentais entre os governos subnacionais e a União devem ser formais ou informais?

O Senado Federal - onde os Estados federados estão representados de maneira homogênea e simétrica, cada qual com três cadeiras - não funciona como espaço de relações intergovernamentais, à maneira, por exemplo, do Bundesrat alemão. Ou seja, o Senado não atua como uma Casa em que os Estados e os municípios dialogam e decidem sobre ações coordenadas e cooperativas em temas comuns. O Senado, no Brasil, é mais fiscalizador e autorizador de políticas públicas. No campo das relações exteriores, a agenda da Câmara Alta se concentra em aprovar tratados internacionais, autorizar operações de paz da Organização das Nações Unidas - ONU, avalizar as indicações de chefes de missão diplomática permanente - registre-se que tudo isso é feito sem nenhuma tradição de debate público sobre o impacto da agenda internacional no cotidiano dos Estados federados e dos municípios, ou mesmo na vida do país.

De outra parte, o Brasil tem importante experiência de relações intergovernamentais em três áreas: federalismo fiscal, saúde e educação. Em todas essas experiências acumuladas, diferentes entre si, as características comuns são: 1) a União exerce algum papel de coordenação, mas os Estados e municípios guardam seu espaço de autonomia e de poder decisório sobre suas opções de políticas públicas; 2) a existência de um alto grau de relacionamento técnico entre as partes envolvidas.

De uma perspectiva mais ampla, as relações intergovernamentais se têm realizado com mais informalidade, dependentes de iniciativas de caráter político. Houve uma sensível mudança, a partir do governo do presidente Luiz Inácio Lula da Silva, com a criação da Secretaria de Relações Institucionais da Presidência da República e da Subchefia de Assuntos Federativos - SAF. Uma das inovações do período foi a criação, em 2005, do Comitê de Articulação Federativa - CAF, entre a União e os municípios, para tratar dos assuntos de competência comum.

Esse movimento do governo federal é, a um só tempo, reativo e proativo, em face das ativíssimas relações intergovernamentais municipais, representadas por fortes e bem articulados movimentos associativos, como a Frente Nacional de Prefeitos - FNP e a Confederação Nacional de Municípios-CNM, que, ao longo dos anos 1990, foram estabelecen- 
do espaços de diálogo horizontal e vertical, consolidando sua atuação em prol de uma agenda municipalista perante o governo federal e o Congresso Nacional.

No campo das relações internacionais federativas, a SAF vem atuando no campo da cooperação internacional descentralizada, destacando-se as relações franco-brasileiras e ítalo-brasileiras no campo bilateral, e o processo de integração sul-americana no campo multilateral, com papel de destaque da SAF na aprovação (2004) e instalação (2007) do Foro Consultivo de Municípios, Estados Federados, Províncias e Departamentos do Mercosul.

O Ministério das Relações Exteriores - MRE criou, unilateralmente, órgãos e mecanismos de relações intergovernamentais. Em 1997, surgiu a Assessoria de Relações Federativas - ARF, órgão da assessoria do gabinete do ministro, para lidar com as crescentes demandas federativas (ver Bogea, 2001). Em 2003, a ARF foi transformada em Assessoria Especial de Assuntos Federativos e Parlamentares - Afepa. Outro mecanismo sui generis, considerado inovador (Melantonio Neto, 2001), são os escritórios regionais do MRE (Belo Horizonte, Curitiba, Florianópolis, Manaus, Porto Alegre, Recife, Rio de Janeiro e São Paulo), que funcionam como braços da Afepa; apóiam in situ e auxiliam as ações internacionais de Estados e municípios. Além disso, a Agência Brasileira de Cooperação - $\mathrm{ABC}$, autarquia vinculada ao $\mathrm{MRE}$, atua como facilitadora e promotora da cooperação internacional, como instrumento de política externa federal, valendo-se de boas práticas, recursos e capacidades de órgãos e agências estaduais e municipais brasileiros, levados para outros países.

A incorporação pela Presidência da República e pelo MRE de uma agenda intergovernamental para ações internacionais federativas significa, por si só, o reconhecimento da legitimidade dos entes federados para as relações internacionais. Fato novo nesse cenário, tendo como pano de fundo a preocupação com o potencial de fragmentação das ações internacionais dos governos subnacionais, foi o I Encontro Negociações Internacionais - Estados e Municípios, realizado em Brasília, em 8/8 / 2006, co-organizado pela Fundação Alexandre de Gusmão - Funag e pela Afepa. Pela primeira vez na história do Itamaraty, foram expostas as grandes linhas da política externa brasileira para um público de prefeitos, secretários municipais e estaduais, técnicos e acadêmicos especialistas nessa área de todo o Brasil. 
Do lado dos Estados federados e dos municípios, existem órgãos específicos para o relacionamento com o governo federal? Usualmente, no Brasil, as relações intergovernamentais são de atribuição da Secretaria de Governo ou da Casa Civil das prefeituras e dos governos estaduais. Verifica-se, mais recentemente, o surgimento de secretarias de relações intergovernamentais e/ou de assuntos metropolitanos (nesse caso, apenas nos municípios, para o relacionamento com a região metropolitana em que está inserido). A par desses órgãos mais gerais, há os novos, voltados para as relações internacionais de Estados e municípios, assumindo atribuições intergovernamentais. Coordenado por Clóvis Brigagão (2005), o primeiro diretório brasileiro de relações internacionais federativas, que incluiu todos os Estados e todos os municípios-capitais, apontou notável mudança nas estruturas estaduais e municipais, que passaram a incorporar, em diferentes graus, órgãos e estruturas para as relações internacionais.

Nas relações intergovernamentais intermunicipais, um fato digno de nota ocorreu em maio de 2005, na cidade de Salvador, Bahia: teve lugar o I Fórum de Secretários de Relações Internacionais de Cidades, a partir do qual foi lançada uma proposta de estratégia inicial, sucedida por outros encontros (em Campinas, em 2006; e em Porto Alegre, em 2008).

Pode-se verificar, assim, que existem órgãos do governo federal voltados para as relações internacionais federativas. Os mecanismos de relacionamento são informais, posto não haver uma conferência ou reunião intergovernamental permanente nem um conselho, à maneira do Conselho Nacional de Política Fazendária - Confaz, no federalismo fiscal. O Senado não cumpre esse papel; poderia ou deveria assumi-lo? É inegável que as relações intergovernamentais têm avançado, sem que se possa dizer que tal avanço conduzirá a estruturas formais. $\mathrm{O}$ debate segue aberto.

\section{RELAÇÕES EXTERNAS/POLÍTICA EXTERNA}

Entre os quatro tópicos analisados neste artigo, este é o mais polêmico. A questão principal é: existe diferença entre relações externas (meras relações de um determinado ator com outros atores estrangeiros ou internacionais) e política externa (ações formuladas e executadas visando à inserção internacional planejada)? Em outros termos, pode-se afirmar que Estados e municípios têm, além de relações externas, uma 
política externa subnacional/federativa, dissociada da política externa nacional ou com ela convergente?

As chancelarias, em geral, recusam-se a aceitar que governos subnacionais tenham política externa - considerada mais do que competência exclusiva, monopólio intocável do Estado-nação. A expressão relações internacionais/externas de governos subnacionais, ou relações internacionais federativas - quando se trata de federações -, inclui de maneira mais ampla uma gama de ações, mais ou menos (des)ordenadas, mais ou menos (des)pretensiosas, que compõem um mosaico de relações internacionais oriundas e desenvolvidas fora do âmbito nacional ou central.

Vale mencionar que o Itamaraty criou a expressão diplomacia federativa para denominar as ações internacionais de Estados e municípios brasileiros. Essa expressão foi utilizada pela primeira vez, oficialmente, em um discurso do então chanceler Luiz Felipe Lampreia, realizado no Congresso Nacional, em abril de 1995 (disponível em http: / / www. mre.gov.br, acessado em fevereiro de 2003).

No Brasil, portanto, a paradiplomacia pode ser denominada segundo a perspectiva federal do Itamaraty e da presidência da República (diplomacia federativa e cooperação internacional descentralizada) e subnacional (relações internacionais federativas, política externa federativa). A terminologia variada indica uma visão própria do fenômeno, de acordo com a compreensão que cada ator reserva para ele.

Sem embargo, é lícito afirmar, da perspectiva acadêmico-científica, que alguns governos subnacionais têm, ou tiveram, política externa. As razões para esse fenômeno costumam ser muito díspares, dependendo do referencial de análise. Recordando Keating (2001:11 e ss), as motivações para a paradiplomacia podem ser de natureza econômica, política e cultural. Independentes ou conjugados, esses impulsos tendem a forjar um interesse local ou regional para a projeção internacional, a ponto de criar uma inserção internacional organizada, autônoma e com objetivos de longo prazo, perfeitamente denominável política externa.

É necessário reconhecer que o cenário internacional pós-Guerra Fria fomentou as ações internacionais diretas de governos subnacionais. Democratização, integração e globalização são processos que, ao longo do período recente (desde os anos 1980), propiciaram experiências 
culminantes de política externa federativa no Brasil (Rodrigues, 2004; 2006). Vale citar que, de forma pioneira, o governo de Leonel Brizola, no Estado do Rio de Janeiro (1983-1986), criou a primeira assessoria estadual de relações internacionais.

As organizações intergovernamentais de cooperação, como a ONU e a Organização dos Estados Americanos - OEA, passaram a incorporar, em suas estruturas e em suas agendas, a participação subnacional direta. Documentos globais de profundo alcance, como a Agenda 21 (aprovada em 1992) e a Agenda Habitat (aprovada em 1996), valorizam e reconhecem a legitimidade do poder local nas relações internacionais, na discussão e na decisão sobre os temas globais. O painel da ONU sobre sociedade civil, coordenado pelo ex-presidente Fernando Henrique Cardoso, em seu informe final (Oliveira, 2005), no marco da reforma da ONU, sugere fortemente que os governos subnacionais tenham inserção direta na estrutura onusiana.

Para exemplificar como essa idéia está presente na agenda mais ampla do MRE, veja-se o trecho do discurso do chanceler Celso Amorim, por ocasião do 61ำ aniversário da ONU, celebrado em Brasília, em que ele diz:

Quando penso na ONU e penso nos municípios, lembro de uma frase do Themístocles Cavalcanti, ilustre jurista brasileiro - politicamente nem sempre concordei com suas idéias, mas ilustre jurista -, que dizia: "O homem não vive na União, o homem vive no município". Ele poderia dizer que o homem não vive nas Nações Unidas, o homem vive no município, mas é essa interação entre o local e o global que nos faz, verdadeiramente, avançar (Brasil, 2006).

A par dos aspectos de natureza institucional, de democratização do sistema internacional, que criaram momentum para a paradiplomacia, outra variável - fortíssima e determinante - passou a gerar demandas crescentes para as relações internacionais federativas. Trata-se da projeção internacional comercial dos governos subnacionais.

Essa é uma área em que há clara convergência entre a política externa nacional e as relações externas, ou política externa federativa. Nos Estados Unidos, por exemplo, há larga tradição de os Estados federados promoverem seus produtos diretamente no exterior e manterem escritórios além-fronteiras, sem que a União veja nessa conduta uma 
violação de soberania; ao contrário: somam-se os esforços para projetar comercialmente o país no exterior.

No Brasil, alguns Estados federados e municípios começaram a se lançar diretamente no cenário externo, por questões sobretudo de carestia econômica, em um cenário de endividamento interno e de crise fiscal agravado nos anos 1990, ao mesmo tempo que a globalização e o "Estado-logístico" criaram não apenas oportunidade mas também necessidade de envolvimento dos poderes locais na política externa comercial (Saraiva, 2004; 2006).

Na seara de afirmação de valores, a política externa federativa pode ser um campo fértil para um leque amplo de temas, de políticas sociais a direitos humanos. O caso Crosby versus National Trade Council (2000), em que o Estado americano de Massachusetts aprovou uma lei estadual impondo sanções comercias a Burma, em virtude de violações de direitos humanos nesse país, é paradigmático. A Suprema Corte dos Estados Unidos julgou ilegal a ação do governo estadual por entender que se tratava de assunto da alçada federal. Embora nesse caso a paradiplomacia tenha sido freada (mostrando que há limites), o campo de incidência normalmente é amplo e não sofre restrição do governo central.

A promoção da cultura, do idioma/dialeto, do patrimônio tangível e intangível de uma região ou localidade, tudo pode ser objeto de uma política externa federativa, vinculada ao ensejo de atrair turismo, investimento direto ou ajuda internacional. O caso do Estado do Amapá, nos anos 1990, que projetou sua imagem no exterior, vinculando-a ao desenvolvimento sustentável da Amazônia, é um exemplo extremo de política externa federativa no campo da sustentabilidade ambiental (Rodrigues, 2004).

Finalmente, os processos de integração têm sido poderosos espaços de ação subnacional, seja em sua dimensão primária fronteiriça, seja em sua vocação progressiva de envolver os diversos atores subnacionais no processo. Nesse sentido, a instalação do Foro Consultivo de Municípios, Estados, Províncias e Departamentos do Mercosul, na Cúpula do Mercosul, em 2007, é um avanço sem precedentes no reconhecimento da legitimidade dos governos subnacionais brasileiros em formular e opinar sobre a política externa relativa ao processo de integração (Rodrigues e Kleiman, 2007). Na primeira sessão do Foro, a decisão dos municípios de ter avocado para seu processo dialogal e decisório o 
processo pleno e global da integração mercosulina - não apenas os temas que as chancelarias consideram de interesse subnacional - é um forte indicador de que os atores subnacionais percebem a dimensão que o Foro possibilita à sua legitimidade de atuação internacional (Mercosul, Carta do Rio, 2007). Essa legitimidade será mais ou menos aceita e reconhecida pelos governos centrais à medida que os governos subnacionais provocarem o debate mais amplo do processo de integração, por via de suas recomendações ao Grupo Mercado Comum.

As respostas às dúvidas sobre a existência, pertinência ou legalidade da política externa federativa no Brasil recebem insumos da compreensão dos princípios do federalismo cooperativo e participativo. Nenhum tema de política pública dos países federais deveria existir sem levá-los em consideração. Com a política externa, não deveria ser diferente.

\section{LEGITIMIDADE E ACCOUNTABILITY}

O tema da legitimidade/accountability remete a um ponto crucial: os governos subnacionais têm o direito de participar do processo de formulação e de definição da política externa? Têm o direito de ser consultados sobre matérias de seu interesse específico? Há experiências em países federais que mostram que é possível aos governos subnacionais exercer esse direito, e há casos históricos, como os do Canadá, da Espanha e da Alemanha, em que essa prerrogativa está prevista em seu direito constitucional.

A questão se reveste de imensa atualidade, na medida em que a transnacionalidade da agenda internacional lança um problema definitivo para os governos subnacionais: ter de se adaptar às exigências e aos padrões de conduta (crescentes, cada vez mais complexos) nos mais variados setores da vida humana, sem ter, na maioria das vezes, a oportunidade de se manifestar e influir nas decisões internacionais - conferências que produzem documentos internacionais -, reservada ao decision-making process dos governos federais ou centrais (Rodrigues, 2006).

A celebração de tratados é um desses loci em que os governos subnacionais, usualmente, ou não têm nenhum canal direto de interlocução, ou os canais existentes são insuficientes. Os governos subnacionais não têm como acompanhar a aprovação de tratados que podem vir a afetar - às vezes dramaticamente - sua situação, tampouco têm como se fazer 
ouvidos nesse processo. A exceção é feita aos países federais em que esse direito e sua prática são reconhecidos.

No Brasil, essa é uma discussão incipiente, mas que ganha relevância à medida que se percebe quanto as relações internacionais e o direito internacional condicionam a vida subnacional. Por outro lado, há de se considerar as conseqüências positivas de os governos subnacionais serem atores mais participativos nos processos internacionais, no que respeita ao aumento de eficácia dos acordos internacionais nos territórios de jurisdição subnacional (Silva, 2007).

No entanto, existem áreas em que, mesmo não havendo dúvida sobre a prerrogativa da União em legislar e executar políticas públicas de âmbito internacional, vêm surgindo iniciativas estaduais e municipais visando debater e encontrar soluções para o impacto estadual e local de temáticas internacionais específicas. É o caso, por exemplo, do tema dos refugiados: o Estado de São Paulo instalou, em 1ㅇ/4/2008, o Comitê Estadual dos Refugiados, uma iniciativa que, segundo o representante do Alto Comissariado das Nações Unidas para os Refugiados ACNUR no Brasil, Javier Lopez-Cifuentes, "[...] permitirá a inclusão dos refugiados nas políticas públicas estatuais, facilitando a inclusão dos refugiados em um Estado importante como São Paulo" (ACNUR/Brasil, 2008).

Considerando a perspectiva estritamente jurídica, se a Constituição Federal atribui competências aos entes federados, gerando obrigações e projetando responsabilidades exclusivas, concorrentes e comuns, seria natural e esperado que os assuntos da política externa, diretamente relacionados com as competências da esfera subnacional, fossem objeto de informação e de consultas de iniciativa do governo federal voltadas para os entes federados. Entretanto, não existe essa prática no Brasil, muito menos há mecanismos institucionais nesse campo.

Por que o princípio da publicidade e o imperativo da transparência não podem ser aplicados à política externa com o mesmo peso que se aplicam às matérias internas? O tempo em que a política externa era assunto restrito de diplomatas e de sherpas da política internacional passou. O tempo da democracia participativa na política externa apenas começa, ao menos no Brasil. 


\section{CONCLUSÕES}

As relações internacionais federativas no Brasil indicam uma experiência que, embora recente, já cristaliza um perfil diferenciado, brasileiro. A ausência de previsão constitucional não tem impedido a paradiplomacia de Estados federados e municípios, em alguns casos pujante. Será tal previsão necessária?

As relações intergovernamentais vêm ganhando corpo, ainda em bases informais, mas o diálogo tem se multiplicado.

A política externa federal e as relações externas federativas (cooperação internacional descentralizada, diplomacia federativa ou mesmo política externa federativa) não têm sido excludentes ou rivais, em que pesem o potencial de conflito e as preocupações do Itamaraty.

A legitimidade/accountability da atuação e a influência dos governos subnacionais na política externa nacional tendem a aumentar se for considerado que o impacto dos compromissos internacionais do Brasil aumenta em quantidade e qualidade, com influência direta e profunda nos poderes regionais e locais.

(Recebido para publicação em julho de 2008)

(Versão definitiva em novembro de 2008)

\section{NOTAS}

1. Igualmente denominados governos não-centrais, unidades constituintes, entes federados ou regiões; a terminologia é variável. Adotarei neste artigo a expressão governos subnacionais, utilizada na literatura especializada e em documentos de organizações intergovernamentais (por exemplo, Banco Internacional para a Reconstrução e o Desenvolvimento - BIRD e Banco Interamericano de Desenvolvimento - BID).

2. A denominação específica dos entes federados varia de acordo com a história, o direito constitucional e o idioma de cada país federal. Refiro-me nesta parte às denominações mais utilizadas nas Américas.

3. Forum of Federations/Forum des Fedèrations, ONG internacional sui generis (porquanto integrada por Estados), com sede em Ottawa, Canadá. Mantida por governos de uma dezena de países federais, promove o estudo, a divulgação, o intercâmbio de boas práticas e o aprimoramento do federalismo no mundo. 
4. Sobre o caso argentino, ver o excelente livro coordenado por Iglesias et alii (2008).

5. Não obstante, a Convenção de Viena, de 1969, reconhece acordos de governos subnacionais em duas situações: 1) quando o governo subnacional atua com mandato do governo central (subsidiariedade); 2) quando o Estado estrangeiro aceita o governo subnacional como contraparte legítima.

6. Até dezembro de 2006, havia 53 emendas constitucionais aprovadas e promulgadas.

7. Todas as referências à CF de 1988 citadas neste artigo estão disponíveis em http:// www.planalto.gov.br/ccivil_03/Constituicao/Constitui\%C3\%A7ao.htm.

8. Nesse sentido, pode-se citar o Decreto no 27.595, de 14/2/2007, da Prefeitura do Rio de Janeiro, que tornou público o Protocolo de Intenções do Rio, relativo às medidas que mitiguem os efeitos do aquecimento global nessa cidade.

9. Vale recordar que o Brasil não ratificou a Convenção de Viena sobre Direito dos Tratados - CVDT, de 1969, documento basilar sobre o tema, em virtude de obstáculos surgidos em seu processo de aprovação legislativa. Oficialmente, o país se guia pela Convenção de Havana (1928), em vigor, embora na prática o Itamaraty tenha incorporado informalmente a maior parte das regras da CVDT, tendo em vista que esta é, em grande medida, fruto de codificação do costume. O impasse da aprovação da CVDT explica, em parte, o porquê de o Brasil não dispor de uma lei sobre o processo de celebração de tratados.

\section{REFERÊNCIAS BIBLIOGRÁFICAS}

ACNUR - Alto Comissariado das Nações Unidas para os Refugiados/BRASIL. (2008), Governo de São Paulo Cria Comitê Estadual para os Refugiados. Nota para a Imprensa. Brasília, ACNUR/Assessoria de Imprensa, 31 de março.

ALEMANHA. (1996), A Lei Fundamental da República Federal da Alemanha (ensaio e anotações de Nuno Rogeiro). Coimbra, Coimbra Editora.

ARGENTINA. (1995), Constitución de la Nación Argentina (Texto de 1853/60, con las Reformas de 1866, 1898, 1957 y 1994). Buenos Aires, Abeledo-Perrot.

BLINDENBACHER, Raoul e PASMA, Chandra (eds.). (2007), Dialogues on Foreign Relations in Federal Countries: Comparative Perspectives. Ottawa/Montreal: Forum of Federations/McGill-Queen's University Press (Booklet Series, 5).

BOGEA, Antenor. (2001), Diplomacia Federativa. Do Papel Internacional e das Atividades Externas das Unidades Federativas nos Estados Nacionais. Brasília, CAE/IRBr.

BRANCO, Álvaro Chagas Castelo. (2008), Paradiplomacia \& Entes Não-Centrais no Cenário Internacional. Curitiba, Juruá.

BRASIL. Ministério das Relações Exteriores. (2006), Palavras do Ministro das Relações Exteriores, Embaixador Celso Amorim, na abertura do Seminário As Nações Unidas: Paz, Direi- 


\section{Gilberto Marcos Antonio Rodrigues}

tos Humanos e Desenvolvimento em um Novo Cenário Internacional, por ocasião do 61은 aniversário das Nações Unidas. Brasília, 24 de outubro.

BRIGAGÃO, Clóvis (coord.). (2005), Relações Internacionais Federativas no Brasil. Estadose Municípios. Rio de Janeiro, Gramma/Fundação Ford.

CARRILLO FLÓREZ, Fernando (ed.). (2001), Democracia en Déficit. Gobernabilidad y Desarrollo en América Latina y el Caribe. Washington, BID.

IGLESIAS, Eduardo et alii (coord.). (2008), Las Provincias Argentinas en el Escenario Internacional. Desafíos y Obstáculos en un Sistema Federal. Buenos Aires, CARI/PNUD.

KEATING, Michael. (2001), “Regiones y Asuntos Internacionales: Motivos, Oportunidades y Estrategias", in F. Aldecoa e M. Keating (eds.), Paradiplomacia: Las Relaciones Internacionales de las Regiones. Madrid/Barcelona, Marcial Pons.

LESSA, José Vicente da Silva. (2002), A Paradiplomacia e os Aspectos Legais dos Compromissos Celebrados por Governos Não-Centrais. Brasília, CAE/IRBr.

MEDEIROS, Antonio P. Cachapuz de (org.). (2007), Desafios do Direito Internacional Contemporâneo. Brasília, Funag.

MELANTONIO NETO, Cesário. (2001), "How to Involve the States in Foreign Policy". Federations, vol. 1, no 5 .

MERCOSUL. Carta do Rio. (2007), Foro Consultivo de Municípios, Estados, Províncias e Departamentos de Mercosul, 18 de agosto.

. Mercosul/CMC/DEC no 41/04. Foro Consultivo de Municípios, Estados Federados, Províncias e Departamentos do Mercosul.

OLIVEIRA, Miguel Darcy de. (2005), “Nações Unidas, Novos Atores e Governança Global: Mensagens e Propostas do Painel sobre Sociedade Civil". Política Externa, vol.14, no 2, pp. 55-64.

REZEK, Francisco. (2005), Direito Internacional Público. Curso Elementar (10ạ ed.). São Paulo, Saraiva.

RODRIGUES, Gilberto Marcos Antonio. (2004), Política Externa Federativa. Análise de Ações Internacionais de Estados e Municípios Brasileiros. Tese de doutorado, PUC-SP, São Paulo.

(2006), “Política Externa Federativa. Análise de Ações Internacionais de Estados e Municípios Brasileiros". CEBRI Tese, Rio de Janeiro, CEBRI. Disponível em http:/ / www.cebri.org.br/pdf/315_PDF.pdf.

e KLEIMAN, Alberto. (2007), "The MERCOSUR Committee of Municipalities, States, Provinces and Departaments. Process of Creation and Perspectives". Fifth Annual Conference of the Euro-Latin Study Network on Integration and Trade - ELSNIT, Barcelona, 26 e 27 de outubro. Disponível em: http:/ / www.iadb.org/intal/aplicaciones/ uploads/ponencias/i_foro_ELSNIT_2007_10_02_Rodrigues_Kleiman.PDF.

SARAIVA, José Flávio Sombra. (2004), “A busca de um novo paradigma: política exterior, comércio externo e federalismo no Brasil". Revista Brasileira de Política Internacional, Brasília, ano 47, no 2, pp. 131-162. 
. "Federalismo e Relações Internacionais do Brasil". In: ALTEMANI, H. e LESSA, A. C. (orgs.). Relações Internacionais do Brasil. Temas e agendas. São Paulo, Saraiva, 2006, vol. 2, pp. 429-455.

SILVA, Ana Célia Lobo. (2007), A democratização do processo de negociação de tratados internacionais. A Participação dos Estados federados no Processo de Celebração dos Tratados no Brasil (dissertação de mestrado). Santos, UNISANTOS.

SILVA, José Afonso da. (2003), Curso de Direito Constitucional Positivo. 22a ed. São Paulo, Malheiros.

STUART, Ana Maria. (s/d), "Regionalismo e Democracia: Uma Construção Possível". CEBRI Tese, Rio de Janeiro, CEBRI. Disponível em http://www.cebri.org.br/pdf/ 213_PDF.pdf, acessado em julho de 2008.

SUISSE. (1997), Constitution Fédérale de la Confédération Suisse. Berne, Chancellerie Fédérale.

VIGEVANI, Tullo et alii (orgs.). (2004), A Dimensão Subnacional e as Relações Internacionais. São Paulo, Educ/Edusc/Unesp. 


\section{ABSTRACT}

International Relations by States and Municipalities in Brazil

This article aims to analyze the phenomenon of international diplomatic relations conducted by States and Municipalities in Brazil, based on the methodology used by the Forum of Federations (2007), which developed a comprehensive study of paradiplomacy, with a focus that incorporates Constitutional issues, inter-government relations, foreign relations/foreign policy, and related issues of legitimacy and accountability.

Key words: paradiplomacy; international relations, Brazil; federalism

\section{RÉSUMÉ}

\section{Relations Internationales Fédératives au Brésil}

Dans cet article, on cherche à analyser le phénomène des relations internationales fédératives au Brésil, la paradiplomatie de ses États fédérés et de ses municipalités, à partir de la méthodologie utilisée par le Forum des Fédérations (2007), qui a développé une étude assez complète sur la paradiplomatie, dont l'approche rassemble les questions constitutionnelles, les relations intergouvernementales, les relations extérieures/politique extérieure et la légitimité/accountability en rapport au sujet en question.

Mots-clé: paradiplomatie; relations internationales au Brésil; fédéralisme 